\title{
A POSSIBLE ROLE FOR HISTORY OF MATHEMATICS AND SCIENCE IN MATHEMATICS AND SCIENCE EDUCATION
}

\author{
Paolo Bussotti \\ Commission for the Publication of the National Edition of \\ Federigo Enriques's Works, Italy
}

My research fields are history of mathematics and science, mainly physics and astronomy. I have also published some works on mathematics and physics education (as to these works see Bussotti 2012a; Bussotti 2012b; Pisano-Bussotti, 2012; Bussotti 2013). I have often wondered which role history of science can have inside science education, basically referring to high school and university students. This subject dates back at least at the second half of the 19th century when an important debate took place in Europe as to the most appropriate manner to teach Euclidean geometry. There were various positions: scholars who thought Euclid (fl. $300 \mathrm{BC}$ ) had to be completely abandoned, others who believed that the Elements had to be almost literally taught and, between these two opposite extreme opinions, a series of intermediate ones existed (for this problems see Bussotti, 2012a, where a series of references is presented, too). The discussion on the role of history of science/mathematics inside science/mathematics teaching is hence a long period debate and I have no pretension to provide an answer, but only to point out some questions and to develop a rasoning around them.

General theorizations risk to be too generic without the support of examples, hence I will start with some examples:

a) relation between synthetic and analytic geometry: The Euclidean synthetic geometry is progressively desappearing from high schools: only some basical notions on triangles and parallelism are given. But the studens are completely unaware of the plurality of complex geometrical problems that can be solved by resorting to the Euclidean theory of equivalence and of similarity (through the use of proportions). They remain on the surface of the Euclidean world, without dealing with the most profound questions of plane geometry and, as a matter of fact, barely touching space geometry. As a partial replacement of this lost geometrical world, analytical geometry is taught, in which the data are transcribed into equations so that the reasoning is basically - even if not completely - algebraic rather than geometric. From a didactical point of view, how to judge this situation?

b) nowadays, in the last years of scientific high schools, the differential and integral calculus is taught. The students have generally a good approach to mathemathical analysis. In the integral calculus, one of the easiest operations is to calculate the area of a parabolic segment. One of the most important Archimedes' (287-212 BC) works is dedicated to the quadrature of parabola (Archimedes in Heath, 1897, pp. 233-252). The method of exhaustion is used. Furthermore, the first proposition of Archimedes' methodological work (Archimedes in Heath, 1912) is dedicated to the heuristic and mechanic procedure through which Archimedes reached to square parabolic segment. Despite omologies between exhaustion method and integral calculus, there are evident differences: the former one is based upon an ad absurdum reasoning and there is not the certainty it can be applied to a whole class of problems. An idea, an intuition is necessary, while the latter can be applied uniformely to calculate the 
areas. Thence, does Archimedes' method get only a historical interest or is it useful from a conceptual point of view, too? What is the possible sense of teaching such a method? And what about the other method used by Archimedes, the mechanical one?

c) In last years of the high schools and in the courses of dynamics and rational and analytic mechanics at the university, the whole treatment of physics is almost completely based upon calculus. The concept of energy plays a prominent role. Nevertheless, the man who invented modern physics, Newton (1642-1727), did not know the concept of energy, either resorted to other principles of conservation (a part from the quantity of movement). Furthermore Newton's arguments in his Philosophiae Naturalis Principia Mathematica (first edition 1687) are basically geometrical. Tipically, in the first book, dedicated to rational mechanics, he develops almost every reasoning geometrically and resorts to the concept of limit only in the last (and, of course, fundamental) phase, in which he needs instantaneous sizes. Then he considers how the ratio of two quantities varies when one of the two tends to 0 . The whole reasoning looks completely different from the ones presented at the high school or at the university. Do Newton's methods hold only a historical interest or a didactical one, too?

The attempt to determine a possible role for history of science/mathematics inside high school instruction needs a preliminary consideration: given the current structure of the high-schools programs in all European countries, it is not possible to teach history of science/mathematics in a systematic and profound manner because the students have to deal with a series of other subjects and the insertion of a further and so complex specific teaching would imply a rather radical school-reformation. Nevertheless, history of science/mathematics can have a role. Let us start from our example B), and more in general, from the teaching of differential and integral calculus: here a historical approach can be very useful. I think that, for the students to fully understand the concepts of limit, derivative, integral and the reasons why they were introduced, the revisiting of: 1) the method used by Fermat (1601-1665) to determine the tangents and the maxima and minima of some known curves, as the parabola (with regard to Fermat's contributions to calculus, see Fermat, 1891-1922, I, pp. 133-179); 2) the way in which Leibniz (1646-1716) introduced, geometrically, the concept of differential and his clear conception of a definite integral as the limit of finite sums (as to differential calculus in Leibniz, see, i.e., Leibniz, 1684; as to integral calculus Leibniz, 1686); 3) the kynematical manner in which Newton introduced fluents and fluxions (Newton 1670-71, see also Principia, section I), can be useful steps. Through this procedure, the students would understand the mathematical and physical reasons why calculus was developed, at the same time the geometrical and physical applications would be the starting points of the didactic unity dedicated to the calculus and not the final - and almost perceived as less important - ones. After these cycle of lessons (5-6 lessons), the formalization of these concepts could be presented as, in a sense, a natural consequence of the attempt to determine precise and standard procedures for the problems dealt with in the previous lessons. Furthermore, interesting questions, as the use of potential or actual infinite in mathematics (with the problems and misunderstanding of many mathematicians lived in the 17th and 18th centuries, who interpreted the infinite involved in the concept of limit as an actual infinite whereas it is potential). These questions are also conneted to philosophy, hence a possible common didactic itinerary can be thought, at least for a period, jointly by the teachers of philosophy (in the countries and schools where this subject is taught), physics and mathematics. If this approach does not allow to develop, for example, some methods of integration, or the study of some theorems, this is not important in a high-school, whose scope should be to teach profoundly some concepts and operative procedures, rather than to teach more superficialy a huge series of concepts and procedures. Let us now return to our parabolic segment. After an educative iter as the one described, the student will understand that the area of the parabolic segment can be easily calculated because a complex conceptual-historical itinerary has brought to the introduction and development of mathematical techniques that nowadays can be taught to the young students, too. At this point, it makes sense to speak of Archimedes' methods: they will be presented as the genial resolution given to a series of problems concerning areas and volumes by a mathematician lived in a period in which the comfortable analytical methods did not exists. In this manner the student could appreciate Archimedes' work. But if this historical-critical path is missing the student is legittimate to ask: Why does Archimedes make it complicated such an easy procedure? Thence, in 
the case of differential and integral calculus, the historical approach is useful from a mathematical point of view, because it induces the students to enter into depth of procedures and problems that often are a little bit hidden by a more formal approach. This can arouse students' mathematical curiosity and induce an interest in this subject superior to the one induced by the formal approach. Furthermore, the tracing of a historical itinerary has a great humanistic and moral value: the pupils can appreciate the difficulties encountered by great scientists and the work they needed to overcome such difficulties.

The example $\mathrm{C}$ ) is different: the methods followed by Newton and his physical procedures are difficult. The introduction of an opportune analytical apparatus and the resort to the concept of energy simplify many problems whose original tractation, exclusively based on the concept of force, looks too complicated for high-schools students. Therefore, in this case, the approach used by physics handbooks is, maybe, prefererable because it is far easier. Nevertheless, at the university, in the faculties of physics and mathematics, in the course of mechanics, it is desirable that, together with the approach based on the principles of conservation, the one, in which the sole concept of force is utilzed, is presented, too. A classical example could be the gravitational field of a spheric shell and of a spheric body with a uniform distribution of mass. These problems are dealt with in the handbooks through the concept of potential which - at least explicitely - is not present in Newton. He develops the theory of the attractive forces of the spherical bodies in the 12th section of the first book of the Principia. A comparison between the two methods, jointly with an explanation why, in the course of history of physics, the approach based on the principles of conservations has been added to that based on forces, could open the mind of mathematics and physics students towards different ways of treating the same series of problems. The knoweledge of various methods could help them in their possible research activity, too. In contrast to this, the general knoweledge how Newton used mathematics in his Principia is a problem that goes beyond the cultural and theoretical horizon of the university students and that can be perhaps proposed to the PhD students in history of mathematics or of physics, but that is still a subject of reserach (as to this, see Bussotti-Pisano 2013a, Bussotti-Pisano 2013b, for bibliography, too).

The example A) is different from B) and C). In this case, as far as it concerns the high-schools students, it is not important the history behind Euclidean geometry, rather Euclidean geometry as a theoretical discipline. For, I am convinced that the replacement of synthetic geometry with analytic geometry is negative from a didactical point of view. The reasoning on the figures, the fact that few standard methods exist and that, hence, the students have to apply their ingenuity to solve the problems, the habit to work with few theoretical instruments and, therefore, the need of a creative intellectual work to reach the results the pupils are asked for, all these characteristics are present in the Euclidean geometry, but they are incomparably less necessary in analytical geometry, which is based on, substantially, standard procedures. Because of these reasons, I deem negatively the progressive abandonment of Euclidean geometry at high schools. In contrast to this trend, such discipline looks me the most formative branch of mathematics for high school students. In this case history of mathematics does not enter directly inside didactics, rather a classical historical branch of mathematics - Euclidean geometry - should be one of the bases for mathematical education, but as a finite product, not considered in its development.

Three examples in which history of science/mathematics can be a support for science/mathematics education have been provided as well as a clarification how differentiated these contributions can be. Even if, I am convinced that a general theory on the best manner to insert history of science/mathematics inside science/mathematics education does not exists, I am equally convinced that history can give a fundamental didactical support in almost every brach of mathematics and physics. I have mentioned three examples: but history can be used also to introduce, for example, algebra and trigonometry in the high schools, matrices theory, differential and algebraic geometry at the university. With regard to physics, history can play an important role as to electricity, electro-magnetism and thermodinamics (on this complex filed of phyiscs I refer to Pisano, 2007 and Pisano, 2010, for bibliographical indications, too). In every single case, it is necessary to understand the way in which history can give its contribution to mathematics and physics education because, as above seen, a plurality of approaches are needing according to the different dealt with problems. 


\section{References}

Archimedes (1897). Quadrature of the Parabola. In Heath, T.L. (1897) The works of Archimedes, 233-252 Cambridge University Press, Cambridge. Available at https://archive.org/details/worksofarchimede029517mbp.

Archimedes (1912). The methods of Archimedes recently discovered by Heiberg. A supplement to the Works of Archimedes 1897. Edited by Heath, T.L. Cambridge University Press, Cambridge. Available at https://archive.org/details/ cu31924005730563.

Bussotti, P. (2012). Federigo Enriques e la didattica della matematica. Euclide. Giornale di matematica per i giovani, Electronic journal. First part February 2012, second part April 2012. web site: http://www.euclide-scuola. org/.

Bussotti, P., 2012, history and didactics of mathematics: a problematic relation. Some considerations based on Federigo Enriques's ideas. Problems of Education in the 21st Century, 48, 5-9.

Bussotti, P. (2013). Vittorio Checcucci and his contributions to mathematics education: a historical overview. Problems of Education in the 21st Century, 53, 22-39.

Bussotti, P., Pisano, R. (2013a). On the Conceptual and Civilization Frames in René Descartes' Physical Works. Advances in Historical Studies, 2/3, 106-125. Published Online September 2013. In SciRes http://www.scirp.org/journal/ ahs.

Bussotti, P., Pisano, R. (2013b). On the Jesuit Edition of Newton's Principia. Science and Advanced Researches in the Western Civilization. Advances in Historical Studies, in press.

Fermat, P. (1891-1922). Oeuvres, four volumes plus Supplément aux tomes I-IV. Gautheir-Villars, Paris.

Leibniz, G.W. (1684). Nova methodus pro maximis et minimis, itemque tangentibus, quae nec fractas, nec irrationales quantitates moratur, \& singulare pro illis calculi genus. Acta Eruditorum Anno MDCLXXXIV, 3, 467-473.

Leibniz, G. W. (1686). De geometriae recondita et analysi indivisibilium atque infinitorum. Acta Eruditorum, 5. Reprinted in Leibniz, Mathematische Schriften, Abth. 2, Band III, 226-235.

Newton, I. (1670-71, published 1736). De Methodus Fluxionum et Serierum infinitorum. Available in Whiteside, D.T. (Ed.) (1969). The Mathematical papers of Isaac Newton, 43-47. Cambridge University Press. Cambridge.

Pisano, R. (2007). Note sui Principes de Thérmodynamique di P. de Saint Robert. In: Atti XXIV SISFA, Bibliopolis, Napoli, $129-134$.

Pisano, R. (2010). On Principles in Sadi Carnot's Theory (1824). Epistemological Reflections. Almagest 2/1, 128-179

Pisano, R., Bussotti, P. (2012). Open problems in mathematical modelling and physical experiments: exploring exponential function. Problems of Education in the 21st Century, 50, 56-69.

Received: November 15, 2013

Accepted: December 05, 2013

Paolo Bussotti

PhD., Editor, Commission for the Publication of the National Edition of Federigo Enriques's Works, Via Paolo Lilla, 66, Livorno, 57122 Italy.

E-mail: paolobussotti66@gmail.com 